of the average structure so depicted. It is not so much meteorologists dealing with day-to-day weather as geographers approaching meteorology through climatological normals that are liable to fall into the trap, but in any case it is time that the subject of " trades," etc., in text-books both of meteorology and physical geography, were presented in a manner more calculated to make the student think in terms of the perturbability rather than the fixity of the great windbelts of the globe. Suppose the actual daily circulation, the interchange of air between the equator and the poles, did conform to anything resembling the cast-iron statistical model, what would be the result ? All weather changes, as we know them, would cease, some regions would absolutely never see rain at all, others would literally never be dry, whilst in England, to judge from conditions when the actual distribution of wind and pressure does momentarily coincide with the statistical picture, we should have almost constant cloud and drizzle.

This is no doubtful inference; it is in absolute accord, not merely with common experience of daily weather sequences, but also with the principles of the modern theory of the Polar Front. Sometimes when a great wall of high pressure westward of Ireland interrupts our "westerlies" there occurs something which any one whose mind was fettered by the statistical picture would never allow for, namely, the passage of a northerly current all the way from the Arctic to the tropics, and current in sub-tropical latitudes has, so far as I can see, as much right to be called a "trade" as the shorter equatorward current prevailing when the controlling anticyclone takes up its more usual position about $35^{\circ} \mathrm{N}$. The number of distortions, minor and major, of the mean or average statistical picture is such that there is no criterion for deciding in all cases whether a particular current of air is, or is not, a "trade," or "anti-trade," as the case may be.

October 20 .

$$
\text { L. C. W. Bonacina. }
$$

\section{Weather Prediction from Observations of Gloudlets.}

THE simplicity of the following method of weather prediction is liable to excite incredulity. Nevertheless, our climate is so changeable that the method can be crucially tested on most days within five minutes by any one. I have used it during many years and on hundreds of occasions, and have found it at least as reliable as the, necessarily, belated weather reports given in newspapers. It is so simple that, as it seems to me, every one must know it ; but, apparently, that is not so. In any case, I write only for the man who, perhaps knowing nothing about scientific meteorology, desires to ascertain for himself the kind of weather he is likely to experience during the next few hours.

Though clouds often condense during heavy downpours, they are popularly said to " dissolve in rain." Actually they disappear through evaporation. They " dry up," vanishing like steam out of a kettle, or like ground mist on the morning of a fine summer day. They climb from the horizon, but wax or wane on the way, condensing or thinning. If then the behaviour of the smallest and thinnest fragment of cloud that can be clearly isolated be watched, it is usually possible to predict very quickly and with fair confidence the state of the weather for the next few hours. If the cloudlet waxes visibly, rain is almost certain; if it wanes, fine weather is equally probable; if it neither waxes nor wanes, existing conditions are likely to continue. It is often much easier to be sure of the waning than of the waxing; for the total dis- appearance of the cloudlet eliminates the possibility of observational error.

This method is inapplicable only when the sky is cloudless, or when it is of a uniform grey. It is uncertain when a high wind prevails ; for then continents of cloud, dissolving perhaps but still dropping rain, may drift up from below the horizon. Of course the nearer the cloudlet (the lower it is) the more closely do the conditions in which it floats approximate to those on the ground, and the more easily may it be observed; and, therefore, the more confident may be the prediction. I have often watched a cloudlet diminishing under a grey and dripping blanket of cloud, and made plans for fine weather. It is said that a lenticular cloud may, at the same time, wax at one end and wane at the other. This implies that unlike weather conditions prevail at the two ends-possibly the meeting of a warm with a cold current, or a heating by the sun of one end, but not the other. Personally, I have observed it only when a cold mountain peak causes to windward the formation of a cloud which drifts along its sides, and dissolves to leeward-a pretty phenomenon which, as in some human affairs, gives an appearance of bustle without real progression.

Linked with this matter is the truth that red in the morning usually presages rain, and red in the evening fine weather. It is common knowledge that our prevailing wind is from the west; that only a low sun paints the clouds; that, speaking generally, it paints only those which are somewhat between it and the observer; and only those on which it shines directly. Thus a cloud that lies in the shadow of another which is nearer the sun is not coloured. Given a westerly wind, then, it follows that red in the morning implies that the sun is shining from a wide clear area in the east on clouds that have drifted overhead from the west. That is, it probably means that clouds are gathering. A glance to the west should settle the matter. On the other hand, when the western clouds are painted, that implies that the sun is shining, and the wind blowing, from a clear area beyond, and, therefore, that the clouds are breaking. It follows again that, if the wind be in the east, red in the morning should indicate bright weather and red in the evening rain.

But no matter what the cloud colours, the surest quick weather test is that furnished by the behaviour of a cloudlet, which, very often, may be seen to wax or wane with surprising swiftness.

20 Lennox Road South,

G. Archidel Reid.

Southsea, Hants,

October 27.

\section{Alleged Rhætic Crane Flies.}

IN NATURE of March 7 last, p. 351, reference is made to the discovery of two species of Rhætic crane flies, described by Dr. G. R. Wieland, palæobotanist, in the January number of the American Journal of Science. Copies of Dr. Wieland's paper have only recently reached me, and I was astonished to find, from the very clear photographs and diagrams published therein, that these wings are not dipterous at all. Apart from beetle elytra, the most abundant wings found in the Upper Triassic beds of Ipswich, Queensland (age, Rhætic or a little older), are Homopterous tegmina, most of which belong to the extinct family Scytinopteridæ, ancestral to the Cercopidæ. These tough tegmina have the peculiarity of usually splitting, when fossilised. along the vena dividens,

NO. 2923 , VOL, I I 6] 